\title{
Higher expression of connexin 40 in human atrial tissue of patients with type 2 diabetes who have undergone a coronary artery bypass graft surgery
}

\author{
Pascal Daleau ${ }^{1,2}$, Geneviève Comeau ${ }^{1}$, Dominique Fournier ${ }^{1}$, Dany Patoine ${ }^{1}$, Patrick Mathieu ${ }^{1,3}$, \\ Paul Poirier ${ }^{1,2}$
}

\footnotetext{
${ }^{1}$ Quebec Heart and Lungs Institute, Laval Hospital Research Centre, Quebec, Canada; pascal.daleau@pha.ulaval.ca

${ }^{2}$ Faculty of Pharmacy, Laval University, Quebec, Canada

${ }^{3}$ Faculty of Medicine, Laval University, Quebec, Canada
}

Received 21 November 2009; revised 13 January 2010; accepted 16 January 2010.

\begin{abstract}
Background: Although cardiac-related mortality rates are declining for the general population in the United States, this is not the case for patients with diabetes. Diabetes is a significant independent predictor of atrial fibrillation (AF), the most common cardiac rhythm disturbance responsible for substantial morbidity and mortality. Objectives: This research was designed to evaluate properties of the atrial tissue between patients with and without type 2 diabetes. Heart rate variability (HRV) indices were calculated and expression of Kv1.5, connexin 43 (Cx43), and 40 (Cx40) were compared. Methods: Patients undergoing a CABG were enrolled: 10 with type 2 diabetes and 8 without diabetes, paired for age, gender and co-morbidities such as hypertension and dyslipidemia. All patients showed normal ejection fraction. A sample of right auricular appendix was taken during CABG and $\mathrm{Kv1.5}, \mathrm{Cx} 40$ and $\mathrm{C} \times 43$ protein contents were determined by western blotting and normalized to a-tubulin level. Results: No HRV difference was found between patients with and without diabetes. Cx43 and Kv1.5 levels were unaffected by diabetes ( $p=0.20$ and 0.07 , respectively) whereas Cx40 content was significantly increased by $55 \%(p=0.02)$. Levels of Cx43 phosphorylated and non-phosphorylated forms were non-significantly decreased in patients with diabetes. Conclusion: Patients with type 2 diabetes had higher expression of $\mathrm{Cx} 40$ in the right auricular appendix tissue. In light of other studies having demonstrated a link between AF and Cx40 expression, it is possible that higher prevalence of AF in patients with diabetes is explained, at least partially, by differential expression of gap-junc-
\end{abstract}

tion proteins.

Keywords: Diabetes; Gap Junctions; Atrial Tissue; Atrial Fibrillation

\section{INTRODUCTION}

The prevalence of diabetes is steadily increasing in westernized societies as well as in developing countries. Although the overall cardiac-related mortality rate has been declining for the general population in the United States, this is not the case for patients with diabetes [1]. Of particular significance, diabetes is a risk factor for different heart-related conditions such as coronary artery disease, heart failure, aortic stenosis and arrhythmias [2].

Atrial fibrillation (AF) is the most common arrhythmia and is responsible for substantial morbidity and mortality [3]. In the Framingham study, systemic hypertension and diabetes were found to be independent predictors of AF [4]. For men and women, respectively, diabetes increased by 1.4 and 1.6 fold the risk of developing AF. The risk of developing AF correlates with atrial dilatation, and the presence of left ventricular diastolic dysfunction [5]. Since AF occurs as an ongoing process over time, subtle atrial abnormalities may precede overt atrial dilatation and contractile dysfunction [5-7]. These could be linked to alterations in electrophysiological properties predisposing to $\mathrm{AF}$.

In animal models (mostly streptozotocin-induced diabetes models), diabetes mellitus is responsible for cardiac arrhythmias, probably caused by an excessive lengthening of the cardiac action potential [8]. Several changes in ionic currents have been described in cardiomyocytes isolated from animal models of diabetes, principally a decrease in the transient repolarizing potassium current $\mathrm{I}_{\mathrm{to}}[8,9]$. This effect could possibly be partially mediated by impaired sympathetic nervous system 
activity [10] or by oxidative stress-induced alteration in the glutathione redox state [11].

It should be pointed out that a reduction in $\mathrm{V}_{\max }$, [12] the maximum speed of the rising phase of the action potential, and a prolongation of the QRS complex [13, 14] have been associated with diabetes. Changes in the intercellular electrical coupling through gap junctions could be involved in this effect. Indeed, it was demonstrated that elevated glucose concentrations inhibit gap junction intercellular communication and reduced connexin $(\mathrm{Cx})$ expression in a variety of cells including vascular smooth muscle cells, endothelial cells, and retinal microvessels. It has been proposed that high glucose concentration interfered with gap junction through the activation of protein kinase $C$ [15-18]. In addition, it has been reported in rat model of diabetes that a down-regulation of $\mathrm{Cx} 43$ occurred and is associated with a compensatory over-expression of other Cxs [19,20]. However, direct alteration of gap junctions by diabetes were never assessed in human cardiomyocytes.

The purpose of this study was to evaluate properties of the atrial tissue between patients with and without type 2 diabetes. Heart rate variability (HRV) indices were calculated to evaluate the potential influence of the cardiac autonomic nervous system. Expression levels of Kv1.5 (underlying $\mathrm{I}_{\mathrm{Kur}}$ ), connexin 43 (Cx43), and 40 (Cx40) were compared between patients with and without type 2 diabetes.

\section{RESEARCH DESIGN AND METHODS}

\subsection{Study Design}

Ten subjects with type 2 diabetes and 8 subjects without diabetes undergoing a coronary artery bypass grafting surgery $(\mathrm{CABG})$ were enrolled in this study. Patients in sinus rhythm aged between 35 and 70 were included. Patients with and without type 2 diabetes were paired for age, gender, co-morbidities such as hypertension and dyslipidemia. All patients had to show normal ejection fraction. Exclusion criteria were: 1) previous history of supraventricular arrhythmia, 2) significant hepatic or renal dysfunction (creatinine $>150 \mathrm{mmol} / \mathrm{L}$ ), 3) significant pulmonary or thyroid disease, 4) any connective tissue disease or history of malignancy, 5) episode of recent heart failure, 6) acute coronary syndrome within the last 3 months and, 7) smoking within the previous 3 months. The present study was approved by the local ethical committee of Laval Hospital.

A sample of right auricular appendix was taken at the beginning of the $\mathrm{CABG}$ procedure, and immediately placed in an oxygenated Tyrode solution (in $\mathrm{mM}: \mathrm{NaCl}$ 137, $\mathrm{KCl} 5.4, \mathrm{CaCl}_{2} 1.8, \mathrm{MgCl}_{2} 1, \mathrm{NaHCO}_{3} 12$, $\mathrm{NaH}_{2} \mathrm{PO}_{4} 0.4$, glucose 5.6) at $4{ }^{\circ} \mathrm{C}$. The tissue was sub- sequently immersed in liquid nitrogen and stored at -80 ${ }^{\circ} \mathrm{C}$ for western analyses.

\subsection{Heart Rate Variability}

Heart rate variability (HRV) was derived from a 24-hour Holter monitoring system (Marquette Electronics Inc., Milwaukee, WI) in all subjects during normal daily life activity. HRV derived from 24-hour ambulatory monitoring is reproducible and free of placebo effect [21]. Using frequency domains, power in the low frequency (LF, 0.04-0.15 Hz) that is an index of both sympathetic and parasympathetic activity, and high frequency (HF, $0.15-0.4 \mathrm{~Hz}$ ) that is an index of solely parasympathetic activity, were calculated. LF/HF ratio is the power in low frequency divided by the power in high frequency. Using time domains, the standard deviation of the RR intervals (SDNN), the square root of the mean squared differences of successive RR intervals (rMSSD) and the standard deviation of the average RR intervals calculated over 5-min periods (SDANN) were determined. pNN50 is the proportion of interval differences of successive $\mathrm{NN}$ intervals greater than $50 \mathrm{~ms}$. $\mathrm{NN}$ intervals are the normal-to-normal intervals that include all intervals between adjacent QRS complexes resulting from sinus node depolarizations in the entire 24-hour ECG recording as previously reported [7].

\subsection{Protein Isolation and Western Blot Analysis [22,23]}

Total protein content was determined with bovine serum albumin as standard and subsequently separated with an $8 \%$ denaturing-PAGE. Proteins transferred to Immobilon PVDF membranes were incubated with antibodies for Kv1.5 [Alomone Labs], Cx40 [Chemicon Int.] (polyclonal, raised in rabbit) and $\mathrm{Cx} 43$ [Chemicon Int.] (monoclonal, mouse). Epitopes are residues 513-602 of mouse Kv1.5, gap junction alpha-5 protein of mouse connexin 40 [CxA-5], and residues 252-270 of native sequence from rat cardiac connexin 43, respectively. All primary antibodies specific for these 3 proteins were diluted in TBS-Tween 1:200. Membranes were respectively incubated with secondary antibodies (1:10000 and 1:5000, anti-rabbit [Cedarlane]; 1:100000, anti-mouse [Chemicon Int.]), conjugated with peroxidase. An ECL detection kit [Millipore] was used to reveal the antigen-antibody for subsequent densitometric analysis. $\mathrm{Kv1}$ 1.5, Cx43 and $\mathrm{Cx} 40$ protein levels were normalized to $\alpha$-tubulin level (1:250, polyclonal, raised in rabbit, Abcam).

\subsection{Statistical Analysis}

Patient characteristics, Holter and blood chemistry parameters are reported as mean \pm standard deviation unless otherwise specified (S.D.). Densitometry values are expressed as mean \pm S.E.M. Comparisons between 
groups were performed using an unpaired Student's t-test and a $\mathrm{p}$ value $<0.05$ was considered significant.

\section{RESULTS}

There was no difference in age, body mass index (BMI) and left ventricular ejection fraction between groups (Table 1). As expected, fasting glucose level was significantly higher in patients with diabetes (Table 1). There were no differences in the lipid profile between groups. Also, drug regimen was comparable between groups except for the use of hypoglycaemic agents in patients with diabetes (Table 2). Results from the 24-hour Holter analysis, showed no significant difference in the indices assessed (LF, HF, LF/HF ratio, SDANN, rMSSD, pNN50, mean NN, SDNN) between patients with and without diabetes.

Densitometric analysis showed that Cx43 levels (normalized with $\alpha$-tubulin and tested in triplicate) were unaffected by diabetes (Figure 1, p $=0.20$ ). When compared to control subjects, patients with diabetes had a tendency of having higher expression of Kv1.5 (Figure 3, $\mathrm{p}=0.07$ ), whereas $\mathrm{Cx} 40$ content was significantly increased by $55 \%$ (Figure $2, \mathrm{p}=0.02$ ). We also assessed expression levels of phosphorylated forms of $\mathrm{Cx} 43$. In patients with diabetes, expression levels of the two phosphoisoforms of $\mathrm{Cx} 43$ (P2 and P1) were decreased to $71 \%$ and $64 \%$ of control values respectively. The non-phosphorylated form of $\mathrm{Cx} 43$ (P0) decreased to $79 \%$ of control values. However, these differences were

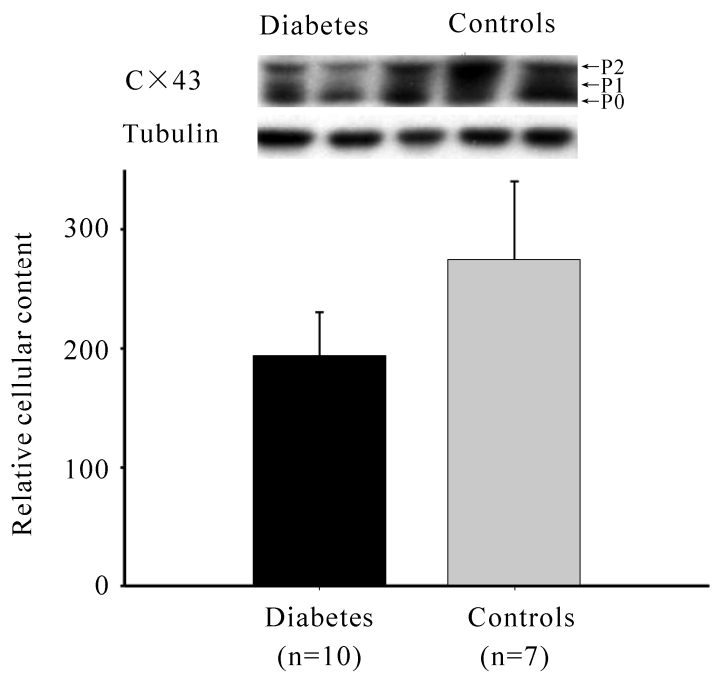

Figure 1. Representative Western blots of right auricular appendix $\mathrm{Cx} 43$ protein level. P0 represents the nonphosphorylated form, while $\mathrm{P} 1$ and $\mathrm{P} 2$ represent two phosphoisophorms of $\mathrm{Cx} 43$. The lower panel shows densitometry of $\mathrm{Cx} 43$ normalized to $\alpha$-tubulin (expressed as $\%$ of tubulin densitometry) in diabetes and control patients (one Control was lacking due to limited tissue availability). Data are means \pm s.e.m.

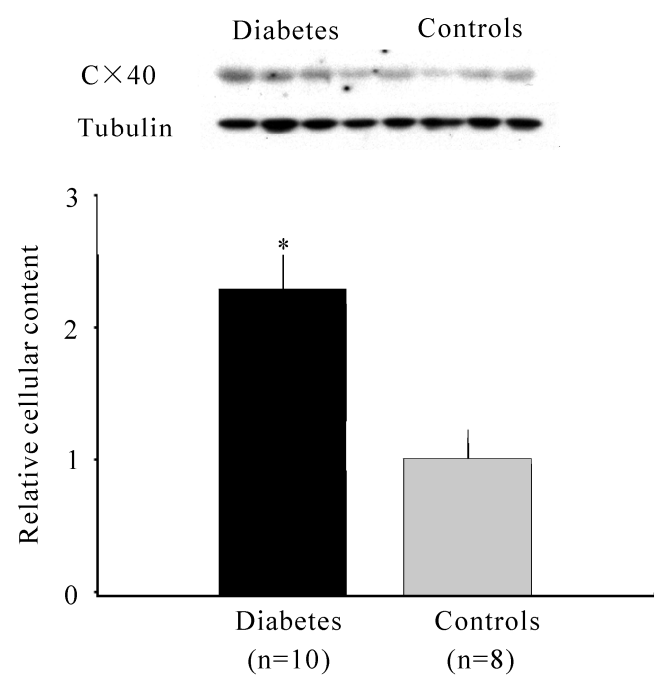

Figure 2. Representative Western blots of right auricular appendix $\mathrm{Cx} 40$ protein level. The lower panel shows densitometry of $\mathrm{Cx} 40$ normalized to $\alpha$-tubulin (expressed as $\%$ of tubulin densitometry) in diabetes and control patients. Data are means \pm s.e.m.; $* P<0.05$.

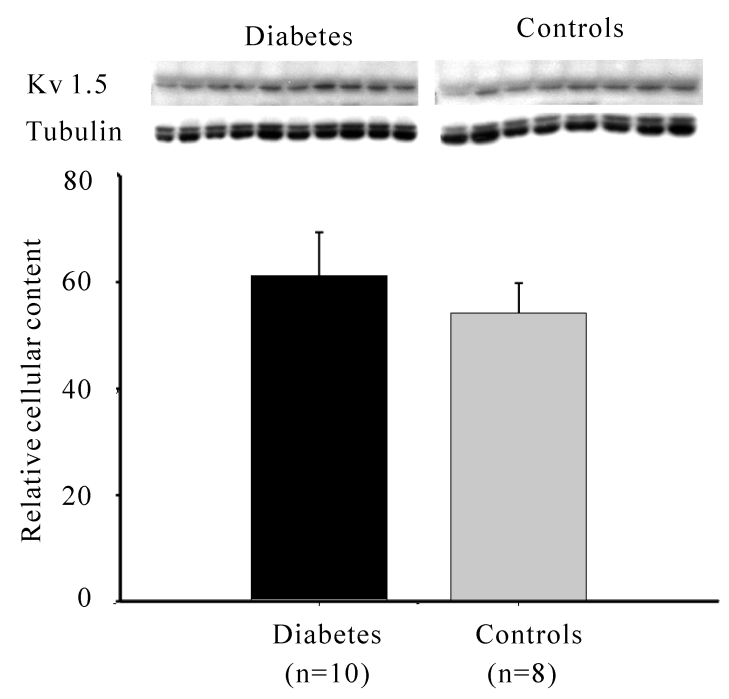

Figure 3. Representative Western blots of right auricular appendix Kv1.5 protein level. For tubulin, only the lower band was considered for densitometric analysis; the upper band was due to a non-specific binding of the Kv1.5 antibody. The lower panel shows densitometry of Kv1.5 normalized to $\alpha$-tubulin (expressed as $\%$ of tubulin densitometry) in diabetes and control patients. Data are means \pm s.e.m.

not significant for all isoforms $(\mathrm{p}=0.46,0.21$ and 0.23 respectively for $\mathrm{P} 0, \mathrm{P} 1$ and $\mathrm{P} 2$ ).

Among patients with diabetes, 50\% (5/10) developed new onset of postoperative AF significant enough (episodes longer than $2 \mathrm{~h}$ or recurrent episodes of AF) to require pharmacological treatment compared to $25 \%$ $(2 / 8)$ in the control group $(\mathrm{p}=0.27)$. 
Table 1. Patient characteristics.

\begin{tabular}{|c|c|c|c|}
\hline & $\begin{array}{c}\text { Diabetes } \\
(\mathrm{n}=10)\end{array}$ & $\begin{array}{l}\text { Controls } \\
(\mathrm{n}=8)\end{array}$ & $\begin{array}{c}\mathrm{P} \\
\text { value }\end{array}$ \\
\hline Age (years) & $61.5 \pm 13.1$ & $68.4 \pm 6.7$ & 0.197 \\
\hline BMI $\left(\mathrm{kg} / \mathrm{m}^{2}\right)$ & $34.1 \pm 7.5$ & $29.5 \pm 4.4$ & 0.198 \\
\hline $\mathrm{EF}(\%)$ & $57.3 \pm 7.1$ & $63.4 \pm 8.7$ & 0.065 \\
\hline Men/Women & $7 / 3$ & $7 / 1$ & 0.815 \\
\hline \multicolumn{4}{|l|}{ Blood analysis: } \\
\hline Glucose $(\mathrm{mmol} / \mathrm{L})$ & $7.2 \pm 1.6$ & $5.2 \pm 0.6$ & 0.003 \\
\hline $\mathrm{HbA}_{1 \mathrm{c}}(\%)$ & $7.1 \pm 1.0$ & - & - \\
\hline Apo B $(g / L)$ & $0.71 \pm 0.18$ & $0.86 \pm 0.21$ & 0.148 \\
\hline \multicolumn{4}{|l|}{ Lipid profile: } \\
\hline Total cholesterol $(\mathrm{mmol} / \mathrm{L})$ & $3.54 \pm 0.62$ & $4.04 \pm 0.81$ & 0.160 \\
\hline Triglycerides $(\mathrm{mmol} / \mathrm{L})$ & $1.72 \pm 0.87$ & $1.82 \pm 0.99$ & 0.756 \\
\hline HDL cholesterol $(\mathrm{mmol} / \mathrm{L})$ & $1.11 \pm 0.14$ & $1.18 \pm 0.27$ & 0.657 \\
\hline LDL cholesterol (mmol/L) & $1.65 \pm 0.48$ & $2.03 \pm 0.50$ & 0.120 \\
\hline Total-C/HDL-C & $3.20 \pm 0.58$ & $3.57 \pm 1.08$ & 0.372 \\
\hline
\end{tabular}

$\mathrm{BMI}=$ Body mass index $; \mathrm{EF}=$ Ejection fraction

Table 2. Co-morbidities and drug regimen in both groups.

\begin{tabular}{lccc}
\hline & $\begin{array}{c}\text { Diabetes } \\
\mathbf{\%}(\mathbf{n}) \\
(\mathrm{n}=10)\end{array}$ & $\begin{array}{c}\text { Controls } \\
\mathbf{\%}(\mathbf{n}) \\
(\mathrm{n}=8)\end{array}$ & P value \\
\hline History & & & \\
Hypertension & $70(7)$ & $62.5(5)$ & 0.107 \\
Dyslipidemia & $70(7)$ & $75(6)$ & 1.000 \\
Smoking & $10(1)$ & $37.5(3)$ & \\
Rx Classes & & & \\
Nitroglycerin & & & 0.143 \\
$\beta$-blockers & $40(4)$ & $50(4)$ & 1.000 \\
CCB & $90(9)$ & $87.5(7)$ & - \\
ACEI & $50(5)$ & -000 & 1.000 \\
ARB & $30(3)$ & $12.5(1)$ & 1.000 \\
$\alpha 1$ inhibitors & $60(6)$ & $12.5(1)$ & 0.125 \\
ASA & $10(1)$ & $87.5(7)$ & - \\
Diuretics & $90(9)$ & - & 0.375 \\
Statins & $40(4)$ & $62.5(5)$ & - \\
Fibrates & $90(9)$ & $12.5(1)$ & - \\
Oral hypoglycemic agents & - & - & 1.000 \\
Benzodiazepine & $100(10)$ & $25(2)$ & - \\
Antidepressants & $10(1)$ & - & \\
\hline
\end{tabular}

\section{DISCUSSION}

This study assessed the effects of type 2 diabetes on the expressions of connexins and Kv1.5 in the human heart. The most important finding of this work is that patients with type 2 diabetes had significantly higher expression of $\mathrm{Cx} 40$ in the right auricular appendix tissue. Apart from the diabetic status, the 2 groups were well matched in terms of age and risk factors, implying that the observed modulation of connexin is likely to reflect the effect of diabetes per se.

\subsection{Expression of Connexins and Modulation by Diabetes}

Assessment of protein content revealed that when compared to control patients, the level of $\mathrm{Cx} 40$ in the right auricular appendix specimens was increased by $55 \%$ in individuals having type 2 diabetes. Similarly, a recent study in rats with streptozotocin-induced diabetes has shown that expression of $\mathrm{Cx} 40$ was increased in retinal microvessels [18]. Although not statistically significant, we also observed a trend toward a decreased expression of $\mathrm{Cx} 43$ in the right auricular appendix tissues of pa- 
tients with type 2 diabetes. All isoforms of Cx43 (the two phosphoisoforms and the non-phosphorylated form), were diminished, although non-significantly. It should be emphasized that in diabetic animal models a reduction in the expression of $\mathrm{Cx} 43$ has been documented in several tissues $[17,24,25]$, including the heart $[18,26]$, though exceptions also exist [27,28].

In one study, while a down-regulation of $\mathrm{Cx} 43$ was demonstrated in retinal microvessels of diabetic rats, an over-expression of $\mathrm{Cx} 40$ and $\mathrm{Cx} 45$ were found [18]. Thus, it seems possible that a down-regulation of one type of connexin is offset by the increased production of another type of gap junction protein. In the same line, a recent study analyzing the expression of connexins in the bladder of diabetic rat reported a lower amount of $\mathrm{Cx} 43$ isoform and higher expression of Cx32 and 26 [17]. However, it has been stressed that the function of one type of connexin cannot necessarily be restored by the presence of another but different member of the connexin family [29]. Hence, this 'replacement' hypothesis certainly deserves more investigations.

\subsection{Atrial Fibrillation, Connexins and $\mathrm{K}^{+}$ Channels}

Diabetes has been reported as a strong and independent risk factor for the development of $\mathrm{AF}[30,31]$. Of note, episodes of postoperative AF have been associated to a higher expression $\mathrm{Cx} 40$ in the right auricular appendix obtained from patients undergoing cardiac surgery [32, $33,34,35]$. It is likely that the relative abundance of $\mathrm{Cx} 43$ and $\mathrm{Cx} 40$ plays an important role in the atrial impulse propagation, and whereby dominance of $\mathrm{Cx} 40$ decreases local propagation velocity [36]. Therefore, the modulation of $\mathrm{Cx} 40$ expression by the diabetic environment could lead to micro-heterogeneities of electrical conduction pattern, promoting by this way episodes of AF.

In different studies with experimental animal models, the activity of several cardiac potassium currents, such as $\mathrm{I}_{\mathrm{to}}, \mathrm{I}_{\mathrm{K}}$ and $\mathrm{I}_{\mathrm{ss}}$, are modulated by diabetes and are possibly involved in the development and/or maintenance of AF [37,38,39]. However, the present results in human right auricular appendix tissue show that Kv1.5 expression remains unchanged in patients with diabetes, suggesting that $\mathrm{I}_{\mathrm{Kur}}$ is not affected. Nevertheless, one cannot exclude a direct modulation of this current by glucose and/or insulin levels.

\subsection{Clinical Implications}

$\mathrm{AF}$ is the most frequent arrhythmia and has been linked to aging as well as to diabetes. While atrial remodeling is undoubtedly an important process participating to the development and the maintenance of AF, an electrophysiological substrate is actively involved in the generation of arrhythmia. In this regard, the dispersion of atrial refractoriness and the ensuing development of multiple reentry wavelets are likely to be important underlying mechanisms pertaining to AF. In this study, the finding of a significant modulation of $\mathrm{Cx} 40$ in patients with diabetes may partly explain the well-documented association between diabetes and AF. By which mechanism diabetes contributes to increase $\mathrm{Cx} 40$ expression in atrial tissue is still unknown, but it is possible that inflammatory and/or oxidative stress pathways [40,41], which are incidentally activated in subjects with diabetes, may contribute to modify the amount of connexins in atrial cardiomyocytes.

\subsection{Limitations}

Insofar patients in the present study had significant coronary artery disease and other co-morbidities, the present findings cannot be inferred to the overall spectrum of patients with diabetes. Particularly, pre-diabetic subjects with glucose intolerance were not studied and may have given further insights as to whether the observed modifications may occur at an earlier stage. In addition, the size of the left atria, which represent atrial remodeling, was not documented in the present study. However, the effect of atrial remodeling, a possible confounding variable, was minimized by having selected a cohort of patients without significant valve disease, a normal ejection fraction, and in sinus rhythm.

\subsection{Conclusions}

In conclusion, we found an up-regulation of $\mathrm{Cx} 40$ protein content in right auricular appendix tissue from patients with type 2 diabetes. In light of other studies having demonstrated a link between AF and Cx40 expression, it is possible that higher prevalence of AF in patients with diabetes is explained, at least partially, by differential expression of gap-junction proteins. Albeit further studies are still needed to understand the full implication of $\mathrm{Cx} 40$ in AF, this study casts some light on a potentially important process occurring in individuals with diabetes, and may open-up new therapeutic and/or research vistas in order to treat and/or prevent $\mathrm{AF}$ in this at-risk population.

\section{ACKNOWLEDGEMENTS}

Drs Paul Poirier and Patrick Mathieu are research scholars from the Fonds de la Recherche en Santé du Québec. This work was supported by operating grants from the Quebec Heart Institute (Drs Paul Poirier and Pascal Daleau) and the Heart and Stroke Foundation of Quebec (Dr Pascal Daleau).

\section{REFERENCES}

[1] Gu, K., Cowie, C.C. and Harris, M.I. (1999) Diabetes and decline in heart disease mortality in US adults. Journal of the American Medical association, 281, 12911297. 
[2] Grundy, S.M., Benjamin, I.J., Burke, G.L., Chait, A., Eckel, R.H., Howard, B.V., Mitch, W., Smith, S.C.Jr. and Sowers, J.R. (1999) Diabetes and cardiovascular disease: a statement for healthcare professionals from the American Heart Association. Circulation, 100, 11341146.

[3] Fuster, V., Ryden, L.E., Cannom, D.S., Crijns, H.J., Curtis, A.B., Ellenbogen, K.A., Halperin, J.L., Le Heuzey, J.-Y., Kay, G.N., Lowe, J.E., Olsson, S.B., Prystowsky, E.N., Tamargo, J.L. and Wann, S. (2006) ACC/AHA Task Force Members, ESC Committee for Practice Guidelines: ACC/AHA/ESC 2006 guidelines for the management of patients with atrial fibrillation: a report of the American College of Cardiology/American Heart Association Task Force on Practice Guidelines and the European Society of Cardiology Committee for Practice Guidelines (Writing Committee to revise the 2001 guidelines for the management of patients with atrial fibrillation) developed in collaboration with the European Heart Rhythm Association and the Heart Rhythm Society. Circulation, 114, e257-e354.

[4] Benjamin, E.J., Levy, D., Vaziri, S.M., D'Agostino, R.B., Belanger, A.J. and Wolf, P.A. (1994) Independent risk factors for atrial fibrillation in a population-based cohort. The Framingham Heart Study. Journal of the American Medical association, 271, 1-11.

[5] Allessie, M.A., Boyden, P.A., Camm, A.J., Kléber, A.G., Lab, M.J., Legato, M.J., Rosen, M.R., Schwartz, P.J., Spooner, P.M., Van Wagoner, D.R. and Waldo, A.L. (2001) Pathophysiology and prevention of atrial fibrillation. Circulation, 103, 769-777.

[6] Poirier, P., Bogaty, P., Garneau, C., Marois, L. and Dumesnil, J.G. (2001) Diastolic dysfunction in normotensive men with well-controlled type 2 diabetes: importance of maneuvers in echocardiographic screening for preclinical diabetic cardiomyopathy. Diabetes Care, 24, 5-10.

[7] Poirier, P., Bogaty, P., Philippon, F., Garneau, C., Fortin, C. and Dumesnil, J.G. (2003) Preclinical diabetic cardiomyopathy: relation of left ventricular diastolic dysfunction to cardiac autonomic neuropathy in men with uncomplicated well-controlled type 2 diabetes. Metabolism, 52, 1056-1061.

[8] Magyar, J., Rusznak, Z., Szentesi, P., Szucs, G. and Kovacs, L. (1992) Action potentials and potassium currents in rat ventricular muscle during experimental diabetes. Journal of Molecular and Cellular Cardiology, 24, 841-853.

[9] Nishiyama, A., Ishii, D.N., Backx,.P.H., Pulford, B.E., Birks, B.R. and Tamkun, M.M. (2001) Altered $\mathrm{K}^{+}$channel gene expression in diabetic rat ventricle: isoform switching between Kv4.2 and Kv1.4. American Journal of Physiology, 281, H1800-H1807.

[10] Gallego, M., Casis, E. and Izquierdo, M.J. (2000) Restoration of cardiac transient outward potassium current by norepinephrine in diabetic rats. Pflügers Archives, 441, 102-107.

[11] Xu, Z., Patel, K., Lou, M.F. and Rozanski, G.J. (2002) Up-regulation of $\mathrm{K}^{+}$channels in diabetic rat ventricular myocytes by insulin and glutathione. Cardiovascular Research, 53, 80-88.

[12] Pacher, P., Ungvari, Z., Nanasi, P.P. and Kecskeméti, V.
(1999) Electrophysiological changes in rat ventricular and atrial myocardium at different stages of experimental diabetes. Acta Physiologica Scandinavica, 166, 7-13.

[13] Yang, Q., Kiyoshige, K., Fujimoto, T., Katayama, M., Fujino, K., Saito, K., Nakaya, Y. and Mori, H. (1990) Signal-averaging electrocardiogram in patients with diabetes mellitus. Japanese Heart Journal, 31, 25-33.

[14] Celiker, A., Akinci, A. and Özin, B. (1994) The signal-averaged electrocardiogram in diabetic children. International Journal of Cardiology, 44, 271-274.

[15] Inoguchi, T., Ueda, F., Umeda, F., Yamashita, T. and Nawata, H. (1995) Inhibition of intercellular communication via gap junction in cultured aortic endothelial cells by elevated glucose and phorbol ester. Biochemical and Biophysical Research Communications, 208, 492-497.

[16] Kuroki, T., Inoguchi, T., Umeda, F., Ueda, F. and Nawata, H. (1998) High glucose induces alteration of gap junction permeability and phosphorylation of connexin-43 in cultured aortic smooth muscle cells. Diabetes, 47, 931-936.

[17] Inoguchi, T., Yu, H.Y., Imamura, M., Kakimoto, M., Kuroki, T., Maruyama, T. and Nawata, H. (2001) Altered gap junction activity in cardiovascular tissues of diabetes. Medical Electron Microscopy, 34, 86-91.

[18] Oku, H., Kodama, T., Sakagami, K., Puro, D.G. (2001) Diabetes-induced disruption of gap junction pathways within the retinal microvasculature. Investigative Ophthalmology and Visual Science, 42, 1915-1920.

[19] Poladia, D.P., Schanbacher, B., Wallace, L.J. and Bauer, J.A. (2005) Innervation and connexin isoform expression during diabetes-related bladder dysfunction: early structural vs. neuronal remodeling. Acta Diabetologica, 42 147-152.

[20] Stilli, D, Lagrasta, C., Berni, R., Bocchi, L., Savi, M., Delucchi, F., Graiani, G., Monica, M., Maestri, R., Baruffi, S., Rossi, S., Macchi, E., Musso, E. and Quaini, F. (2007) Preservation of ventricular performance at early stages of diabetic cardiomyopathy involves changes in myocyte size, number and intercellular coupling. Basic Research in Cardiology, 102, 488-499.

[21] Task Force of the European Society of Cardiology and the North American Society of Pacing and Electrophysiology: Heart rate variability (1996) Standards of measurement, physiological interpretation, and clinical use. European Heart Journal, 17, 354-381.

[22] Daleau, P., Boudriau, S., Michaud, M., Jolicoeur, C. and Kingma, J.G. Jr. (2001) Preconditioning in the absence or presence of sustained ischemia modulates myocardial Cx43 protein levels and gap junction distribution. Canadian Journal of Physiology and Pharmacology, 79, 371378.

[23] Sarrazin, J.-F., Comeau, G., Daleau, P., Kingma, J., Plante, I., Fournier, D. and Molin, F. (2007) Reduced incidence of vagally-induced atrial fibrillation and expression levels of connexins by $\mathrm{n}-3$ polyunsaturated fatty acids in dogs. Journal of the American College of Cardiology, 50, 1505-1512.

[24] Lin, H., Ogawa, K., Imanaga, I. and Tribulova, N. (2006) Alterations of connexin 43 in the diabetic rat heart. $A d$ vance in Cardiology, 42, 243-254.

[25] Okruhlicova, L., Tribulova, N., Misejkova, M., Kucka, M., Stetka, R., Slezak, J. and Manoach, M. (2002) Gap 
junction remodeling is involved in the susceptibility of diabetic rats to hypokalemia-induced ventricular fibrillation. Acta Histochemica, 104, 387-391.

[26] Sheu, J.-J., Chang, L.-T., Chiang, C.-H., Sun, C.-K., Chang, N.-K., Youssef, A.A., Wu, C.-J., Lee, F.-Y. and Yip, H.-K. (2007) Impact of diabetes on cardiomyocyte apoptosis and connexin43 gap junction integrity. Role of pharmacological modulation. International Heart Journal, 48, 233-245.

[27] Brink, P.R., Valiunas, V., Wang, H.Z., Zhao, W., Davies, K. and Christ, G.J. (2006) Experimental diabetes alters connexin43 derived gap junction permeability in shortterm cultures of rat corporeal vascular smooth muscle cells. Journal of Urology, 175, 381-386.

[28] Howarth, F., Nowotny, N., Zilahi, E., El Haj, M. and Lei, M. (2007) Altered expression of gap junction connexin proteins may partly underlie heart rhythm disturbances in the streptozotocin-induced diabetic rat heart. Molecular and Cellular Biochemistry, 305, 145-151.

[29] Wolfle, S.E., Schmidt, V.J., Hoepfl, B., Gebert, A., Alcolea, S., Gros, D. and de Wit, C. (2007) Connexin45 cannot replace the function of connexin40 in conducting endothelium-dependent dilations along arterioles. Circulation Research, 101, 1292-1299.

[30] Östgren, C.J., Merlo, J., Råstam, L. and Lindblad, U. (2004) Atrial fibrillation and its association with type 2 diabetes and hypertension in a Swedish community. Diabetes, Obesity and Metabolism, 6, 367-374.

[31] Movahed, M.-R., Hashemzadeh, M. and Jamal, M.M. (2005) Diabetes mellitus is a strong, independent risk for atrial fibrillation and flutter in addition to other cardiovascular disease. International Journal of Cardiology, 105, 315-318.

[32] Dupont, E., Ko, Y.-S., Rothery, S., Coppen, S.R., Baghai, M., Haw, M. and Severs, N.J. (2001) The gap-junctional protein connexin 40 is elevated in patients susceptible to postoperative atrial fibrillation. Circulation, 103, 842849.

[33] Polontchouk, L., Haefliger, J.-A., Ebelt, B., Schaefer, T., Stuhlmann, D., Mehlhorn, U. and Kuhn-Regnier, F. (2001) Effects of chronic atrial fibrillation on gap junction distribution in human and rat atria. Journal of the
American College of Cardiology, 38, 883-891.

[34] Kostin, S., Klein, G., Szalay, Z., Hein, S., Bauer, E.P. and Schaper, J. (2002) Structural correlate of an atrial fibrillation in human patients. Cardiovascular Research, 54, 361-379.

[35] Wetzel, U., Boldt, A., Lauschke, J., Weigl, J., Schirdewahn, P., Dorszewski, A., Doll, N., Hindricks, G., Dhein, S. and Kottkamp, H. (2005) Expression of connexins 40 and 43 in human left atrium in atrial fibrillation of different aetiologies. Heart, 91, 166-170.

[36] Beauchamp, P., Yamada, K.A., Baertschi, A.J., Green, K., Kanter, E.M., Saffitz, J.E. and Kléber, A.G. (2006) Relative contributions of connexins 40 and 43 to atrial impulse propagation in synthetic strands of neonatal and fetal murine cardiomyocytes. Circulation Research, 99, 1216-1224.

[37] Zhang, Y., Xiao, J., Lin, H., Luo, X., Wang, H., Bai, Y., Wang, J., Zhang, H., Yang, B. and Wang, Z. (2007) Ionic mechanisms underlying abnormal QT prolongation and the associated arrhythmias in diabetic rabbits: a role of rapid delayed rectifier $\mathrm{K}^{+}$current. Cellular Physiology and Biochemistry, 19, 225-238.

[38] Lengyel, C., Virag, L., Biro, T., Jost, N., Magyar, J., Biliczki, P., Kocsis, E., Skoumal, R., Nanasi, P.P., Toth, M., Kecskemeti, V., Papp, J.G. and Varro, A. (2007) Diabetes mellitus attenuates the repolarization reserve in mammalian heart. Cardiovascular Research, 73, 512520.

[39] Casis, O., Gallego, M., Iriarte, M. and Sanchez-Chapula, J.A. (2000) Effects of diabetic cardiomyopathy on regional electrophysiologic characteristics of rat ventricle. Diabetologia, 43, 101-109.

[40] Fernandez-Cobo, M., Gingalewski, C., Drujan, D. and De Maio, A. (1999) Downregulation of connexin 43 gene expression in rat heart during inflammation. The role of tumour necrosis factor. Cytokine, 11, 216-224.

[41] Fukuda, T., Ikejima, K., Hirose, M., Takei, Y., Watanabe, S. and Sato, N. (2000) Taurine preserves gap junctional intercellular communication in rat hepatocytes under oxidative stress. Journal of Gastroenterology, 35, 361368. 